\title{
Dabigatran etexilate versus warfarin in management of non-valvular atrial fibrillation in UK context: quantitative benefit-harm and economic analyses
}

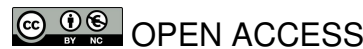

\author{
Joshua Pink PhD student ${ }^{1}$, Steven Lane lecturer in medical statistics ${ }^{2}$, Munir Pirmohamed professor \\ of clinical pharmacology ${ }^{3}$, Dyfrig A Hughes professor of pharmacoeconomics ${ }^{1}$
}

${ }^{1}$ Centre for Health Economics and Medicines Evaluation, Institute of Medical and Social Care Research, Bangor University, Bangor, Gwynedd LL57 1UT, UK; ${ }^{2}$ Centre for Medical Statistics and Health Evaluation, University of Liverpool, Liverpool, UK; ${ }^{3}$ Wolfson Centre for Personalised Medicine, Department of Molecular and Clinical Pharmacology, Institute of Translational Medicine, University of Liverpool

\begin{abstract}
Objectives To determine the incremental net health benefits of dabigatran etexilate $110 \mathrm{mg}$ and $150 \mathrm{mg}$ twice daily and warfarin in patients with non-valvular atrial fibrillation and to estimate the cost effectiveness of dabigatran in the United Kingdom.

Design Quantitative benefit-harm and economic analyses using a discrete event simulation model to extrapolate the findings of the RE-LY (Randomized Evaluation of Long-Term Anticoagulation Therapy) study to a lifetime horizon.

Setting UK National Health Service.

Population Cohorts of 50000 simulated patients at moderate to high risk of stroke with a mean baseline $\mathrm{CHADS}_{2}$ (Congestive heart failure, Hypertension, Age $\geq 75$ years, Diabetes mellitus, previous Stroke/transient ischaemic attack) score of 2.1 .
\end{abstract}

Main outcome measures Quality adjusted life years (QALYs) gained and incremental cost per QALY of dabigatran compared with warfarin.

Results Compared with warfarin, low dose and high dose dabigatran were associated with positive incremental net benefits of $0.094(95 \%$ central range -0.083 to 0.267$)$ and 0.146 (-0.029 to 0.322$)$ QALYs.

Positive incremental net benefits resulted for high dose dabigatran in $94 \%$ of simulations versus warfarin and in $76 \%$ of those versus low dose dabigatran. In the economic analysis, high dose dabigatran dominated the low dose, had an incremental cost effectiveness ratio of £23 082 (€26 700; \$35 800) per QALY gained versus warfarin, and was more cost effective in patients with a baseline $\mathrm{CHADS}_{2}$ score of 3 or above. However, at centres that achieved good control of international normalised ratio, such as those in the UK, dabigatran $150 \mathrm{mg}$ was not cost effective, at $£ 42386$ per QALY gained.

Conclusions This analysis supports regulatory decisions that dabigatran offers a positive benefit to harm ratio when compared with warfarin.
However, no subgroup for which dabigatran $110 \mathrm{mg}$ offered any clinical or economic advantage over $150 \mathrm{mg}$ was identified. High dose dabigatran will be cost effective only forpatients at increased risk of stroke or for whom international normalised ratio is likely to be less well controlled.

\section{Introduction}

Atrial fibrillation is the most common sustained cardiac arrhythmia, with an estimated prevalence in the United Kingdom of $10 \%$ in patients aged 75 or over and an associated fivefold increase in the risk of ischaemic stroke. ${ }^{12}$ Bed days for patients with a primary or secondary diagnosis of atrial fibrillation cost the National Health Service (NHS) £1.9bn (€2.2bn; \$2.9bn) in 2008, with outpatient and other inpatient costs totalling $£ 329 \mathrm{~m}^{3}$

Warfarin is the mainstay of oral thromboprophylactic anticoagulation treatment. ${ }^{4}$ However, patients show considerable variability in their response to warfarin, which, coupled with a narrow therapeutic range, necessitates frequent monitoring and adjustment of dosage to ensure optimal anticoagulation. Deviations outside the therapeutic range (international normalised ratio (INR) 2.0-3.0) increase the risk of both strokes and haemorrhagic events. ${ }^{5}$

Dabigatran etexilate is a new oral direct thrombin inhibitor that may provide an alternative to warfarin; it has the advantage of not requiring regular monitoring. In the multinational, Randomized Evaluation of Long-Term Anticoagulation Therapy (RE-LY) study, 18113 patients with non-valvular atrial fibrillation and at least one risk factor for stroke were randomised to one of two doses of dabigatran $(110 \mathrm{mg}$ or 150 $\mathrm{mg}$, twice daily) or dose adjusted warfarin. ${ }^{6}$ After a median follow-up of two years, the rates of the primary outcome (stroke or systemic embolism) were similar to those for warfarin among 
patients assigned the lower dose but were lower among patients assigned the higher dose $(1.11 \% v 1.71 \%$ per year; relative risk $0.66,95 \%$ confidence interval 0.53 to $0.82 ; \mathrm{P}=0.0001)$.

Compared with warfarin, the annual rate of major bleeding was lower among patients assigned dabigatran $110 \mathrm{mg}(2.71 \% \mathrm{v}$ $3.36 \%$; relative risk $0.80,0.69$ to $0.93 ; \mathrm{P}=0.003$ ) but similar among those assigned $150 \mathrm{mg}$. Dabigatran was associated with higher rates of myocardial infarction, but these were not statistically significant.?

The US Food and Drug Administration (FDA) was satisfied of the positive benefit to harm balance of dabigatran but failed to identify a subgroup of patients in which the benefit-harm profile was superior for the $110 \mathrm{mg}$ dose compared with the $150 \mathrm{mg}$ dose and consequently approved only the higher dose. ${ }^{8}$ However, both doses have been approved by other regulatory authorities, including the European Medicines Agency, which specifies 150 $\mathrm{mg}$ twice daily for patients under 80 years of age and $110 \mathrm{mg}$ twice daily for those aged 80 and over or as an option when the thromboembolic risk is considered to be low and the risk of bleeding is high. ${ }^{9}$

Against this background, we describe a quantitative analysis of the trade-off between thrombotic and bleeding risks-events that have differential effects on life expectancy and quality of life - as a basis to guide clinicians' prescribing. We also develop a health economic evaluation to estimate the cost effectiveness of dabigatran in patients with non-valvular atrial fibrillation, given the considerable uncertainty about its cost effectiveness in the UK healthcare setting.

\section{Methods}

We modelled the net benefits and expected lifetime clinical event rates of each dose of dabigatran and warfarin to quantify the benefits and harms of competing treatments, while accounting for uncertainties in parameters. ${ }^{10}{ }^{11}$ We estimated incremental net benefits as the difference between treatments in quality adjusted life years (QALYs), a preference based outcome measure that combines two dimensions of health-life expectancy and health related quality of life.

In the economic analysis, we extended the model to estimate resource use and costs from the perspective of the UK NHS. The primary outcome was the incremental cost per QALY gained.

We developed a discrete event simulation model that considers individual patients, their characteristics, and their experience of clinical events and outcomes according to the passage of time. ${ }^{12}$ After each event, a patient's health profile is updated, leading to a new set of probabilities for future events. Costs and QALYs are accrued from the patient's health states and the events that occur.

For each treatment, we generated identical cohorts of 50000 patients, each assigned an age and health profile defined by the presence/absence (according to the trial protocol ${ }^{13}$ ) of any of the following characteristics at baseline: hypertension, diabetes mellitus, congestive heart failure, previous stroke, previous transient ischaemic attack, previous myocardial infarction, and previous intracranial haemorrhage (table $1 \Downarrow){ }^{6}$ We assumed health characteristics to be independent in the base case analysis but did a sensitivity analysis to assess the effect of correlation. We used $\mathrm{R}$ for all analyses.

\section{Clinical parameter estimates}

We searched Medline, Embase, the Cochrane library, and the FDA and ClinicalTrials.gov websites during July 2010 to identify relevant trials of dabigatran in atrial fibrillation. We used "dabigatran," "BIBR 1048," and "atrial fibrillation" as search terms and identified three phase II trials (PETRO, ${ }^{26}$ PETRO-Ex,${ }^{14}$ and NCT01136408 ${ }^{14}$ ) and a single phase III trial (RE-LY). ${ }^{6}$ The phase II studies included too few patients receiving the licensed dose and were of too limited a duration (12 weeks) to provide useful data on reduction in stroke event rate. The five year, open label extension to PETRO did not include warfarin as a comparator. We therefore used the RE-LY study for annualised clinical event rates (table $2 \Downarrow$ ), ${ }^{6}{ }^{14}$ and the patients modelled consequently represented those of RE-LY (box 1).

Our analysis considered the probability of (and reasons for) discontinuation of treatment to better reflect the "real world" use of oral anticoagulants. At two years, this had occurred in $21 \%$ of patients randomised to dabigatran and $17 \%$ of those randomised to warfarin. ${ }^{6}{ }^{14} \mathrm{We}$ assumed that patients who discontinued dabigatran because of a bleed or who discontinued warfarin (for any reason) had been switched to aspirin. We assumed that patients who discontinued dabigatran for reasons other than bleeds were switched to warfarin, but we tested this in a sensitivity analysis.

Incidence rates for hypertension and diabetes mellitus came from general population data, ${ }^{29}{ }^{30}$ as did age specific mortality rates from non-vascular causes, ${ }^{31}$ all with the assumption that these adequately reflect the RE-LY population (table $2 \Downarrow$ ). The relative risks of thromboembolic events and bleeds with aspirin (versus warfarin) came from a published meta-analysis of comparative trials. ${ }^{27}$ Box 2 lists key modelling assumptions.

\section{Utility estimates}

We took the permanent utility decrement associated with stroke from the results of the European Stroke Prevention Study, using the proportions of disabling and non-disabling strokes from RE-LY (45\% of non-fatal strokes are non-disabling). The baseline health state utility for a person with atrial fibrillation (adjusted for age), as well as the decrements associated with other cardiovascular sequelae and haemorrhagic adverse events, came from a report of EQ-5D utility scores elicited from several thousand respondents to the US Medical Expenditure Panel Survey. ${ }^{15}{ }^{17}$ Utility losses in patients receiving warfarin (for example, as a consequence of regular monitoring) and aspirin (assumed to be the same for dabigatran; for example, because of gastrointestinal upset) came from a study of 83 patients with atrial fibrillation. ${ }^{16}$ Table 1 shows all utility values; multiple utility decrements for an individual patient are assumed to be additive.

\section{Resource use and cost estimates}

All costs (besides those of dabigatran) are reported in 2009 $\operatorname{GBP}(£)$. We inflated costs incurred during the first and subsequent years after stroke or myocardial infarction from 2006/7 prices. ${ }^{18}$ Costs included in this figure were ward costs (staffing, equipment, consumables, and overheads) and procedure costs (which also included the cost of hospital drugs), inpatient and outpatient costs, costs of general practitioners' and district nurses' visits, and the costs of other drugs. ${ }^{18}$ The costs of pulmonary emboli and transient ischaemic attacks came from NHS reference costs, ${ }^{19}$ as did those for managing major and minor bleeds, following the methods and definitions of a report by the National Institute for Health and Clinical Excellence (NICE) on the costing of atrial fibrillation. ${ }^{20}$

Incidences of other adverse events did not differ significantly between treatment groups, so we did not deem attaching a cost 


\section{Box 1: Population modelled}

The population modelled reflected patients in the RE-LY study, ${ }^{6}$ who were $63.6 \%$ male and $70 \%$ white, with a mean age of 71.5 years, a mean weight of $82.6 \mathrm{~kg}$, and no contraindication to anticoagulation. Mean baseline $\mathrm{CHADS}_{2}$ (Congestive heart failure, Hypertension, Age $\geq 75$ years, Diabetes mellitus, previous Stroke/transient ischaemic attack) score was 2.1, and $32.4 \%$ of patients had a score of 3 or more; $50.4 \%$ of patients were naive to vitamin $\mathrm{K}$ antagonists.

\section{Box 2: Assumptions made in constructing model}

- The risk of future cardiovascular events for each simulated patient, at any given time, is determined by their age, current treatment, and $\mathrm{CHADS}_{2}$ score (a stroke risk index based on age, diagnosis of hypertension, diabetes or congestive heart failure, and previous stroke or transient ischaemic attack, ${ }^{34}$ ) according to probabilities determined from RE-LY (table $2 \downarrow$ )

- Clinical event rates (including for myocardial infarction) would remain constant over time, unless a change occurred in one or more of the risk factors

- The rates of discontinuation of treatment in the second year of the RE-LY study persisted for the lifetime of treatment

- The incidence (though not the prevalence) of hypertension and diabetes was the same in patients with atrial fibrillation as in the general population, as were deaths from non-vascular causes

to such events to be necessary. The exception to this is the higher incidence of dyspepsia in the dabigatran groups- $11.8 \%$ for $110 \mathrm{mg}$ and $11.3 \%$ for $150 \mathrm{mg}$, compared with $5.8 \%$ for warfarin - which we accounted for by including the cost of proton pump inhibitors. The proportion of patients taking proton pump inhibitors came from RE-LY, and the number of capsules per patient came from a published cost effectiveness analysis. ${ }^{21}$ The relative proportion of patients using proton pump inhibitors in conjunction with aspirin came from a randomised controlled trial of antithrombotic treatments. ${ }^{28}$

We based the costs of warfarin and associated monitoring on a micro-costing analysis of 165 patients with atrial fibrillation included in a six month prospective cohort study, with the cost of starting warfarin excluded from the long term maintenance cost. $^{22}$ The average use of aspirin in practice came from a published costing study. ${ }^{32}$

Drug acquisition costs came from the British National Formulary and the NICE appraisal consultation document for dabigatran. ${ }^{23}{ }^{24}$ Table $1 \Downarrow$ shows all costs.

\section{Discounting}

We applied an annual discount rate of $3.5 \%$ to costs, life years, and QALYs to reflect time preference but not to discrete clinical events. ${ }^{25} 33$

\section{Age adjusted dosing}

In age adjusted dosing, patients initially below the age of 80 years start on the $150 \mathrm{mg}$ dose of dabigatran, and those aged 80 or above start on the $110 \mathrm{mg}$ dose. If a person reaches 80 and is still continuing with the $150 \mathrm{mg}$ dose, he or she is then switched to the $110 \mathrm{mg}$ dose. We modelled this regimen in two different ways. Our primary method used the results of a post hoc subgroup analysis, ${ }^{14}$ which subdivided people by age. The secondary method used the event rates from the full trial for patients taking either dose.

\section{Sensitivity and scenario analyses}

We did univariate sensitivity analyses of each parameter in the model to assess the stability of the results when key assumptions are tested. We based ranges for parameters on $95 \%$ confidence intervals where available, or, alternatively, on plausible percentage ranges (web extra table A). We tested the possibility that the cost of managing intracranial haemorrhage and gastrointestinal bleeding may be higher with dabigatran than with warfarin, because of the lack of an appropriate reversal agent, by increasing the costs to consider the potential use of prothrombin complex concentrates (non-activated or activated). ${ }^{35}{ }^{36}$

Our base case assumes that the benefit of treatment persists for the lifetime of patients. We tested two further scenarios: one in which the benefit persisted for two years and a second in which the benefit decreased linearly to zero over the 10 years after the trial.

We did a probabilistic sensitivity analysis, implementing a Monte Carlo simulation of 2000 sets of simulated parameters (table $1 \Downarrow$, web extra table $\mathrm{B}$ ), to estimate the $95 \%$ central ranges for clinical event rates and net health benefits. In the economic analysis, we used the probabilistic sensitivity analysis to consider the joint uncertainty in costs and QALYs to estimate the probabilities of dabigatran being cost effective at different thresholds, presented as a cost effectiveness acceptability curve, and in different clinical scenarios.

We did subgroup analyses to calculate the net health benefits (and associated 95\% central ranges), the incremental cost effectiveness ratios, and the probability of cost effectiveness, in the following pre-specified populations ${ }^{14}{ }^{37-39}$ : patients aged 75 or older; patients with a $\mathrm{CHADS}_{2}$ (Congestive heart failure, Hypertension, Age $\geq 75$ years, Diabetes mellitus, previous Stroke/transient ischaemic attack) score of 2, or a $\mathrm{CHADS}_{2}$ score of 3 or more; patients who have previously had a stroke or transient ischaemic attack; patients attending trial centres (clinics) reporting mean INR time within the therapeutic range of more (or less) than $65.5 \%$; patients on warfarin whose time within the therapeutic range was more (or less) than $66.8 \%$, compared with the full dabigatran populations (only summary information was available for this calculation); patients with poor renal function as indicated by a low $(30-50 \mathrm{~mL} / \mathrm{min})$ creatinine clearance; and patients who were naive to vitamin $\mathrm{K}$ antagonist treatment.

\section{Results}

The results of our simulation at two years matched the results of the trial. No value deviated by more than $2.1 \%$ (data not shown), a level of variability that would be expected given the stochastic nature of the simulation.

\section{Clinical outcomes and net health benefit}

In the base case analysis, dabigatran $110 \mathrm{mg}$ and $150 \mathrm{mg}$ twice daily extended life by 1.1 and 2.4 months compared with warfarin (table $3 \Downarrow$ ). The corresponding incremental net benefits were 0.094 (95\% central range -0.083 to 0.267$)$ and 0.146 ( -0.029 to 0.322 ) QALYs. Compared with the low dose of 
dabigatran, the higher dose was associated with a positive incremental net benefit in $76 \%$ of simulations and with a mean value of 0.052 ( -0.122 to 0.228$)$ QALYs. Compared with warfarin, dabigatran $110 \mathrm{mg}$ and $150 \mathrm{mg}$ twice daily were associated with positive incremental net benefits in $86 \%$ and $94 \%$ of simulations.

Lifetime incidences of stroke or systemic embolism were $12.5 \%$ lower with dabigatran $110 \mathrm{mg}$ twice daily than with warfarin and $27.4 \%$ lower with dabigatran $150 \mathrm{mg}$ twice daily. Incidences of major haemorrhagic events were lower for low dose dabigatran (by 4.0\%) but higher for high dose dabigatran (by $8.8 \%$ ). We found no discernible differences in lifetime incidences of myocardial infarction between the two doses of dabigatran, but these were about $19 \%$ higher than for warfarin. Although age adjusted dabigatran dosing was associated with lower bleeding rates, the higher rates of thrombotic events resulted in it being inferior to the $150 \mathrm{mg}$ dose with respect to QALYs and life years gained.

\section{Costs and cost effectiveness}

Total discounted lifetime costs for dabigatran $110 \mathrm{mg}$ and 150 mg twice daily and warfarin were $£ 10529, £ 9850$, and $£ 6480$. These were made up mainly of drug and monitoring costs, which accounted for $47.3 \%$ and $44.2 \%$ of the overall costs of the two doses of dabigatran compared with $22.4 \%$ for warfarin. The costs of managing strokes or systemic emboli accounted for $39.1 \%, 40.2 \%$, and $57.6 \%$ of total costs; the remainder was accounted for by the costs of managing other events.

The incremental cost effectiveness ratio (ICER) for low dose dabigatran versus warfarin was $£ 43074$ per QALY gained; that for high dose dabigatran was $£ 23082$ per QALY gained (table $4 \Downarrow$ ). Dabigatran $110 \mathrm{mg}$ twice daily was dominated as a strategy by dabigatran $150 \mathrm{mg}$ twice daily, as it was associated with a worse health outcome (-0.052 QALYs) and higher cost (£679).

\section{Age adjusted dosing}

The use of dabigatran $110 \mathrm{mg}$ twice daily from the age of 80 years was dominated by the $150 \mathrm{mg}$ twice daily dose under both possible modelling methods. In the models based on the post hoc subgroup analysis and using full RE-LY data, the use of the lower dose accrued 0.005 and 0.017 fewer QALYs and cost $£ 62$ and $£ 234$ more over a lifetime. Compared with warfarin, the ICERs for use of low dose dabigatran in the over-80s were $£ 24340$ and $£ 27940$ per QALY gained for the two methods.

\section{Sensitivity analysis}

The tornado plot (fig $1 \Downarrow$ ) indicates the sensitivity of incremental net benefits to stroke rates and the duration of effect of dabigatran. Dabigatran $150 \mathrm{mg}$ twice daily was cost effective at the lower threshold of $£ 20000$ per QALY when we assumed decreases (or increases) in the rates of stroke or vascular death in patients receiving dabigatran (or warfarin) or increases in either clinical event costs or utility losses. Compared with warfarin, the ICER for dabigatran $110 \mathrm{mg}$ twice daily exceeded $£ 32415$ per QALY in all sensitivity analyses (data not shown).

The probabilistic sensitivity analysis (fig $2 \Downarrow$ ) indicates that warfarin had the highest probability of being cost effective at thresholds of $£ 24400$ or lower. Dabigatran $150 \mathrm{mg}$ twice daily was the most probable cost effective option at thresholds above that value. Considering a pair-wise comparison between warfarin and dabigatran $150 \mathrm{mg}$ twice daily, warfarin was the most cost effective treatment at thresholds of $£ 22800$ and below.

\section{Subgroup analyses}

Among the subgroups analysed, the mean incremental net health benefit consistently favoured both doses of dabigatran over warfarin and dabigatran $150 \mathrm{mg}$ twice daily over $110 \mathrm{mg}$ twice daily (fig $3 \Downarrow$ ).

Dabigatran 150 mg twice daily was within the $£ 30000$ per QALY cost effectiveness threshold for all subgroups of patients other than in centres with mean time within the therapeutic range for INR of at least $65.5 \%$ (table $4 \Downarrow$ ). Dabigatran $150 \mathrm{mg}$ twice daily was most cost effective in patients at high risk of stroke $\left(\mathrm{CHADS}_{2}\right.$ score $\left.\geq 3\right)$, but even here the probability of it being cost effective was only $68 \%$. Dabigatran $110 \mathrm{mg}$ twice daily, when used for all ages or restricted to patients aged 80 or over, was dominated by the higher dose in all subgroups (data not shown).

\section{Discussion}

Our quantitative benefit-harm analysis found that dabigatran was associated with positive net health benefits when compared with warfarin. High dose dabigatran was the most clinically effective option. Greatest benefits were evident in patients in whom control of INR is poorest (patients' time within the therapeutic range $<66.8 \%$ ) and fewest benefits in centres that achieve good INR control (centre time within therapeutic range $\geq 65.5 \%$ ). We were unable to identify a subgroup of patients in which the lower dose of dabigatran - when used for all ages or restricted to patients aged 80 or over-was superior to the higher dose. The benefits of reduced bleeding rates with the lower dose were offset by reduced efficacy in preventing stroke. These findings are in accordance with the results of the RE-LY study, ${ }^{6}$ and related subgroup analyses, ${ }^{14}{ }^{37-39}$ and lend support to the FDA's rationale for not licensing the $110 \mathrm{mg}$ dose. ${ }^{8}$

The economic analysis indicated that for the overall RE-LY study population, dabigatran $150 \mathrm{mg}$ twice daily is potentially a cost effective alternative to warfarin, at $£ 23082$ per QALY gained. However, its probability of being cost effective at a threshold of $£ 20000$ per QALY is only $45 \%$. This uncertainty is driven largely by rates of stroke and, to a lesser extent, vascular death and the cost of managing strokes. NICE's criteria for decision making state that "above a most plausible ICER of $£ 20,000$ per QALY gained, judgements about the acceptability of the technology as an effective use of NHS resources will specifically take account of . . the degree of certainty around the ICER. . . NICE will be more cautious about recommending a technology when it is less certain about the ICERs presented." ${ }^{25}$ Dabigatran $110 \mathrm{mg}$ twice daily is not a cost effective option, and the age adjusted dosing regimen was dominated in all scenarios by the $150 \mathrm{mg}$ dose.

High dose dabigatran was more cost effective in patients at a greater risk of stroke (baseline $\mathrm{CHADS}_{2}$ score $\geq 3$ ). However, at centres that achieve good INR control (centres' time within therapeutic range $\geq 65.6 \%$ ), dabigatran $150 \mathrm{mg}$ twice daily is no longer cost effective, at $£ 42386$ per QALY gained. Although the mean time within the therapeutic INR range in the UK of $72 \%$ in the RE-LY study may be higher than routine practice, ${ }^{22} 37$ so too might adherence to dabigatran, which requires twice daily dosing compared with warfarin's once.

\section{Comparison with other studies}

We are not aware of any quantitative benefit-harm analyses of dabigatran in atrial fibrillation. However, two economic evaluations of dabigatran in non-valvular atrial fibrillation have 
been published. Both used Markov models to estimate lifetime cost effectiveness on the basis of the RE-LY trial.

The US study, which adopted the costing perspective of a health insurer, ${ }^{40}$ yielded a quality adjusted life expectancy of 10.28 with warfarin, 10.70 with low dose dabigatran, and 10.84 with high dose dabigatran. These are considerably higher than our estimates, primarily because of patients' starting age which, at 65 years, was 6.1 years younger than in our analysis based on the RE-LY population. Nevertheless, despite this difference, similar results were obtained with respect to dabigatran $150 \mathrm{mg}$ twice daily being associated with positive incremental net health benefits across a range of risks for stroke and intracranial haemorrhage, compared with dabigatran $110 \mathrm{mg}$ twice daily and warfarin. A similar economic outcome also resulted; the ICER fell just below the cost effective threshold but had a high level of uncertainty, driven mostly by drug costs and stroke rates.

The Canadian study, ${ }^{41}$ sponsored by the manufacturer of dabigatran and based on RE-LY patient level data (though not listed as a pre-specified analysis), ${ }^{13}$ assessed its cost effectiveness according to the same age adjusted dosing schedule as approved in Europe. In contrast to the US study and our study, however, dabigatran was deemed to be cost effective compared with warfarin, at \$C10 440 (£6466; €7468; \$10 026) per QALY gained. Differences relate largely to costs, which were proportionally much greater for the management of events and long term care in the Canadian analysis. Considering a patient taking dabigatran who has an acute stroke and five years of follow-up costs, in our analysis the cost of stroke is about five times higher than the cost of drugs whereas in the Canadian study it is more than 15 times higher.

\section{Strengths and weaknesses}

Our analysis benefited from application of a discrete event simulation method, which is the method of choice for conditions in which no obvious discrete disease states exist into which patients can be classified, a necessary assumption for a Markov model. ${ }^{12}$ It allows for a much larger number of potential health states to be modelled and removes the need to define the additional structural parameters necessary for a Markov model (such as cycle length). A discrete event simulation also operates in continuous rather than discrete time, thus more naturally approximating actual patients' histories and allowing continuous parameters (such as age) to be more appropriately modelled.

Our analysis counters the concerns raised by NICE in its appraisal of the manufacturer's submission, ${ }^{24}$ through the inclusion of the age adjusted dosing regimen, use of reliable estimates of INR monitoring cost, continuation of dyspepsia throughout the duration of dabigatran treatment, and independence from treatment of the risks of disability and death after stroke. We had no access to data on the quality of life sub-study of RE-LY, and we made no attempt at modelling a typical UK population with atrial fibrillation, who are typically older, with proportionately more women, and have a different risk profile for stroke than the RE-LY trial population. ${ }^{42}$ Patients are also less likely to persist with anticoagulant treatment in routine practice than in a clinical trial setting ${ }^{42}$ but we had no additional data for more elaborate modelling. ${ }^{43}$

Several caveats exist. Firstly, the reliance on the RE-LY study as the sole source of clinical data is a potential cause for concern. Although RE-LY is one of the largest trials of atrial fibrillation, this makes assessing the effect of any possible weaknesses in the design of the RE-LY study difficult (for example, its open label design, a significant proportion of patients taking aspirin concomitantly, and only about a third of patients with a baseline $\mathrm{CHADS}_{2}$ score $\geq 3$ ). We were further limited by not having access to data for individual patients. Our a priori decision to base our analysis on the entire RE-LY study population may limit the generalisability of the base case estimates to a UK context. Subgroups, defined by centres achieving better INR control and patients in the higher categories of risk for stroke, may result in more relevant estimates of ICER.

Secondly, the necessity of bringing together data from a wide variety of sources has the potential to introduce bias into the analysis. For example, relative event rates for aspirin treatment came from a separate study, which will have had different demographics and different warfarin dosing schedules from RE-LY. Extrapolation of a two year trial to a lifetime horizon also raises questions, as does the assumption that utility decrements for events derived from the general population are appropriate for patients with atrial fibrillation. However, approximations such as these are unavoidable in economic modelling. Thirdly, we did not include the possibility that widespread use of dabigatran might affect the provision of anticoagulation clinic services, as we considered displacement of warfarin by dabigatran to such an extent to be unlikely.

\section{Implications for practice and future research}

Dabigatran has advantages over warfarin; the most important are that monitoring is not needed, that anticoagulation for a given dose is more predictable, and that fewer drug-drug interactions are likely. However, it also has disadvantages. ${ }^{44}$ Firstly, the lack of monitoring provides little ability to objectively monitor adherence, which in the real world setting is likely to be worse with dabigatran given the need for twice daily dosing and its associated higher incidence of dyspepsia. Secondly, if the patient has a serious bleed, no proven antidotes exist. ${ }^{45}$ Thirdly, some uncertainty exists about dosing in certain clinical settings such as renal failure, old age, and concomitant intake of amiodarone, which may lead to either underdosing or overdosing given that no pharmacodynamic marker for monitoring exists. Fourthly, the safety and efficacy of thrombin inhibitors in the longer term (beyond two years) are uncertain, although the follow-up study of RE-LY patients should yield valuable information. ${ }^{46}$

An important finding from the cost effectiveness analysis is that dabigatran is not cost effective when compared in patients whose INR is well controlled or in centres that achieve good INR control. Part of the reason for such variability in the time within the therapeutic range with warfarin is the presence of genetic polymorphisms in the CYP2C 9 and VKORC1 genes. ${ }^{22}{ }^{47}$ At least four randomised trials are running globally in which genotype guided prescribing of warfarin, which is predicted to improve the time within the therapeutic range, is being tested against current clinical care. Whether dabigatran would be cost effective against genotype guided prescribing of warfarin is unclear and needs further evaluation. Furthermore, other competitors to dabigatran are due to be evaluated for licensing soon, such as rivaroxaban and apixaban, which have shown similar clinical effectiveness to warfarin but have not been tested against dabigatran. ${ }^{48}$ Thus, although the arrival of new anticoagulants should be welcomed, their place in the prevention of strokes in patients with atrial fibrillation in comparison with warfarin (perhaps genotype guided) needs further evaluation. In the end, a stratified approach may represent the best approach to maximise both the clinical effectiveness and cost effectiveness of anticoagulation in patients with atrial fibrillation. 


\section{What is already known on this topic}

Dabigatran etexilate is an alternative thromboprophylactic agent to warfarin for patients with non-valvular atrial fibrillation However, uncertainty exists about its dose, balance of benefits and harms, and cost effectiveness

Previous cost effectiveness analyses of dabigatran for this indication have shown conflicting results and have not used appropriate modelling approaches

\section{What this study adds}

Dabigatran was associated with positive incremental net benefits versus warfarin, but dabigatran $110 \mathrm{mg}$ twice daily did not offer clinical or economic advantage over $150 \mathrm{mg}$ twice daily in any subgroup

Dabigatran is unlikely to be cost effective in clinics, such as those in the UK, able to achieve good control of the international normalised ratio (INR) with warfarin

Dabigatran $150 \mathrm{mg}$ twice daily, and an age adjusted dosing regimen, will be cost effective only for patients at increased risk of stroke or for whom INR is likely to be less well controlled

Contributors: DAH had the idea for the study, oversaw its design, contributed to the interpretation of the data, and redrafted the paper. JP did all the analyses, interpreted the results, and drafted the paper. $\mathrm{SL}$ and MP assisted in the design of the study, interpretation of results, and discussion of the findings. All authors revised the paper for important intellectual content. All authors have approved the final version of the paper. DAH is the guarantor.

Funding: The study was funded by the Medical Research Council, as part of the North West Hub in Trial Methodological Research (NWHTMR). The sponsors of the study had no role in study design, data collection, data analysis, data interpretation, or writing of the report.

Competing interests: All authors have completed the Unified Competing Interest form at www.icmje.org/coi_disclosure.pdf (available on request from the corresponding author) and declare: JP and DAH have support from the Medical Research Council for the submitted work; no relationships that might have an interest in the submitted work in the previous three years; no non-financial interests that may be relevant to the submitted work.

Ethical approval: Not needed.

Data sharing: No additional data available.

1 Lip GYH, Tse HF. Management of atrial fibrillation. Lancet 2007;370:604-18.

2 Hobbs FD, Fitzmaurice DA, Mant J, Murray E, Jowett S, Bryan S, et a. A randomised controlled trial and cost-effectiveness study of systematic screening (targeted and total population screening) versus routine practice for the detection of atrial fibrillation in people aged 65 and over: the SAFE study. Health Technol Assess 2005;9:1-74

3 Office of Health Economics. Estimating the direct costs of atrial fibrillation to the NHS in the constituent countries of the UK and at SHA level in England. Office of Health Economics, 2009.

4 National Collaborating Centre for Chronic Conditions. Atrial fibrillation: national clinical guideline for management in primary and secondary care. Royal College of Physicians, 2006 .

5 Connolly SJ, Pogue J, Eikelboom J, Flaker G, Commerford P, Franzaosi MG, et al. Benefit of oral anticoagulation over antiplatelet therapy in atrial fibrillation depends on the quality of international normalized ratio control achieved by centers and countries as measured by time in therapeutic range. Circulation 2008;118:1029-37.

6 Connolly SJ, Ezekowitz MD, Yusuf S, Eikelboom J, Oldgren J, Parekh A, et al. Dabigatran versus warfarin in patients with atrial fibrillation. N Engl J Med 2009;361:1139-51

7 Connolly SJ, Ezekowitz MD, Yusuf S, Reilly PA, Wallentin L, RE-LY Investigators. Newly identified events in the RE-LY trial. N Engl J Med 2010;363:1875-6.

8 Beasley BN, Unger EF, Temple R. Anticoagulant options-why the FDA approved a higher but not a lower dose of dabigatran. N Engl J Med 2011;364:1788-90.

9 European Medicines Agency. Pradaxa product information. 2011. www.ema.europa.eu/ docs/en GB/document_library/EPAR _. Product Information/human/000829/ WC500041059.pdf.

10 Hughes DA, Bayoumi AM, Pirmohamed M. Current assessment of risk-benefit by regulators: is it time to introduce decision analyses? Clin Pharmacol Ther 2007;82:127-30

11 Garrison LP Jr, Towse A, Bresnahan BW. Assessing a structured, quantitative health outcomes approach to drug risk-benefit analysis. Health Aff (Millwood) 2007:26:684-95

12 Caro JJ, Möller J, Getsios D. Discrete event simulation: the preferred technique for health economic evaluations. Value in Health 2010;13:1056-60.

13 Ezekowitz MD, Connolly S, Parekh A, Reilly PA, Varrone J, Wang S, et al. Rationale and design of RE-LY: randomised evaluation of long-term anticoagulant therapy, warfarin, compared with dabigatran. Am Heart J 2009;157:805-10.

14 Boehringer Ingelheim. Advisory committee briefing document-dabigatran etexilate. Food and Drug Administration, 2010 (available at www.fda.gov/downloads/advisorycommittees/ committeesmeetingmaterials/drugs/cardiovascularandrenaldrugsadvisorycommittee/ ucm226009.pdf)

15 Sullivan PW, Ghushchyan V. Preference-based EQ-5D index scores for chronic conditions in the United States. Med Decis Making 2006;26:410-20.

16 Gage BF, Cardinalli AB, Owens DK. The effect of stroke and stroke prophylaxis with aspirin or warfarin on quality of life. Arch Intern Med 1996;156:1829-36.
17 Meckley LM, Gudgeon JM, Anderson JL, Williams MS, Veenstra DL. A policy model to evaluate the benefits, risks and costs of warfarin pharmacogenomic testing. Pharmacoeconomics 2010;28:61-74.

18 Hemingway $\mathrm{H}$. The effectiveness and cost-effectiveness of biomarkers for the prioritisation of patients awaiting coronary revascularisation: a systematic review and decision model. Health Technol Assess 2010;14(9):1-151

19 Department of Health. NHS reference costs 2008/09. DH, 2009 (available at www.dh.gov. uk/en/Publicationsandstatistics/Publications/PublicationsPolicyAndGuidance/DH_111591).

20 National Institute for Health and Clinical Excellence. Atrial fibrillation: the management of atrial fibrillation. Costing report: implementing NICE guidance in England. NICE, 2006 (available at www.nice.org.uk/nicemedia/pdf/CG036costingreport.pdf).

21 Leontiadis GI, Sreedharan A, Dorward S, Barton P, Delaney B, Howden CW, et al. Systematic reviews of the clinical effectiveness and cost-effectiveness of proton pump inhibitors in acute upper gastrointestinal bleeding. Health Technol Assess 2007;11(51):1-164.

22 Jorgensen AL, Al-Zubiedi S, Zhang JE, Keniry A, Hanson A, Hughes DA, et al. Genetic and environmental factors determining clinical outcomes and cost of warfarin therapy: a prospective study. Pharmacogenet Genomics 2009;19:800-12.

23 British Medical Association, Royal Pharmaceutical Society of Great Britain. British national formulary. BMA, RPS, 2010 (No 59.)

24 National Institute for Health and Clinical Excellence. Atrial fibrillation-dabigatran etexilate: appraisal consultation document. 2011. http://guidance.nice.org.uk/TA/Wave21/10/ Consultation/DraftGuidance.

25 National Institute for Health and Clinical Excellence. Guide to the methods of technology appraisal. London: NICE, 2008.

26 Ezekowitz MD, Reilly PA, Nehmiz G, Simmers TA, Nagarakanti R, Parcham-Azad K, et al. Dabigatran with or without concomitant aspirin compared with warfarin alone in patients with nonvalvular atrial fibrillation (PETRO study). Am J Cardiol 2007;100:1419-26.

27 Hart RG, Pearce LA, Aguilar MI. Meta-analysis: antithrombotic therapy to prevent stroke in patients who have nonvalvular atrial fibrillation. Ann Intern Med 2007;146:857-67.

28 Cleland JGF, Findlay I, Jafri S, Sutton G, Falk R, Bulpitt C, et al. The Warfarin/Aspirin Study in Heart Failure (WASH): a randomized trial comparing antithrombotic strategies for patients with heart failure. Am Heart J 2004;148:157-64

29 Diabetes UK. Diabetes prevalence 2010. 2010. www.diabetes.org.uk/Professionals/ Publications-reports-and-resources/Reports-statistics-and-case-studies/Reports/Diabetesprevalence-2010/.

30 Eastern Region Public Health Observatory. Modelled estimates and projections of hypertension for local authorities in England. 2008. www.erpho.org.uk/viewResource. aspx?id=17904.

31 Wilmoth JR, Shkolnikov V. The human mortality database. 2006. www.mortality.org/.

32 Drummond A. Cost of aspirin and statins in general practice. Q J Med 2002;95:23-26

33 Torgerson DJ, Raftery J. Economic notes: discounting. BMJ 1999;319:914-5.

34 Gage, B.F. Stroke risk stratification in patients taking aspirin. Circulation 2004;110:2287-92.

35 Van Ryn J, Standier J, Haertter S, Liesenfeld KH, Wienen W, Feuring M, et al. Dabigatran etexilate: a novel, reversible, oral direct thrombin inhibitor: interpretation of coagulation assays and reversal of anticoagulant activity. Thromb Haemost 2010;103:1116-27.

36 Guest JF, Watson HG, Limaye S. Modeling the cost-effectiveness of prothrombin complex concentrate compared with fresh frozen plasma in emergency warfarin reversal in the United Kingdom. Clin Ther 2010;32:2478-93.

37 Wallentin L, Yusuf S, Ezekowitz MD, Alings M, Flather M, Franzosi MG, et al. Efficacy and safety of dabigatran compared with warfarin at different levels of international normalised ratio control for stroke prevention in atrial fibrillation: an analysis of the RE-LY trial. Lancet 2010;376:975-83.

38 Diener HC, Connolly SJ, Ezekowitz MD, Wallentin L, Reilly PA, Yang S, et al. Dabigatran compared with warfarin in patients with atrial fibrillation and previous transient ischaemic attack or stroke: a subgroup analysis of the RE-LY trial. Lancet Neurol 2010:9:1157-63.

39 Ezekowitz MD, Wallentin L, Connolly SJ, Parekh A, Chernick MR, Paque J, et al. Dabigatran and warfarin in vitamin $\mathrm{K}$ antagonist naive and experienced cohorts with atrial fibrillation. Circulation 2010;122:2246-53.

40 Freeman JV, Zhu RP, Owens DK, Garber AM, Hutton DW, Go AS, et al. Cost-effectiveness of dabigatran compared with warfarin for stroke prevention in atrial fibrillation. Ann Intern Med 2011:154:1-11.

41 Sorensen SV, Kansal AR, Connolly S. Cost-effectiveness of dabigatran etexilate for the prevention of stroke and systemic embolism in atrial fibrillation: a Canadian payer perspective. Thromb Haemost 2011;105:908-15.

42 Gallagher AM, Rietbrock S, Plumb J, van Staa TP. Initiation and persistence of warfarin or aspirin in patients with chronic atrial fibrillation in general practice: do the appropriate patients receive stroke prophylaxis? J Thromb Haemost 2008:6:1500-6.

43 Hughes D, Cowell W, Koncz T, Cramer J. Methods for integrating medication compliance and persistence in pharmacoeconomic evaluations. Value Health 2007;10:498-509.

44 Hankey GJ, Eikelboom JW. Dabigatran etexilate: a new oral thrombin inhibitor. Circulation 2011;123:1436-50.

45 Rolfe S, Papadopoulos S, Cabral KP. Controversies of anticoagulation reversal in life-threatening bleeds. J Pharm Pract 2010;23:217-25. 
46 RELY-ABLE long term multi-center extension of dabigatran treatment in patients with atrial fibrillation who completed RE-LY trial. www.clinicaltrials.gov/ct2/show/NCT00808067? term=RELY\&rank=2.

47 International Warfarin Pharmacogenetics Consortium, Klein TE, Altman RB, Eriksson N, Gage BF, Kimmel SE, et al. Estimation of the warfarin dose with clinical and pharmacogenetic data. N Engl J Med 2009;360:753-64.

48 Ahrens I, Lip GYH, Peter K. What do the RE-LY, AVERROES and ROCKET-AF trials tell us for stroke prevention in atrial fibrillation? Thromb Haemost 2011;105:574-8.

Accepted: 08 September 2011

\section{Cite this as: BMJ 2011;343:d6333}

This is an open-access article distributed under the terms of the Creative Commons Attribution Non-commercial License, which permits use, distribution, and reproduction in any medium, provided the original work is properly cited, the use is non commercial and is otherwise in compliance with the license. See: http://creativecommons.org/licenses/bync/2.0/ and http://creativecommons.org/licenses/by-nc/2.0/legalcode. 


\section{Tables}

\section{Table 1| Patients' baseline characteristics, costs, health state utilities, and discount rate parameters used in model}

\begin{tabular}{|c|c|c|c|}
\hline Parameter & Value & Probabilistic sensitivity analysis distribution & References \\
\hline \multicolumn{4}{|l|}{ Baseline characteristics ${ }^{*}$} \\
\hline Hypertension & $14283 / 18113$ & $\beta(14283,3830)$ & 6,14 \\
\hline Diabetes & $4221 / 18113$ & $\beta(4221,13892)$ & 6,14 \\
\hline Heart failure & $5793 / 18113$ & $\beta(5793,12320)$ & 6,14 \\
\hline Previous stroke & $2273 / 18113$ & $\beta(2273,15840)$ & 6,14 \\
\hline Previous transient ischaemic attack & $1663 / 18113$ & $\beta(1663,16450)$ & 6,14 \\
\hline Previous myocardial infarction & $3005 / 18113$ & $\beta(3005,15108)$ & 6,14 \\
\hline Previous intracranial haemorrhage & $713 / 18113$ & $\beta(713,17400)$ & 6,14 \\
\hline \multicolumn{4}{|l|}{ Health state utilities } \\
\hline Atrial fibrillation (age 67) & 0.774 & $1-\gamma(43.06,0.0052)$ & 15 \\
\hline Stroke (permanent disutility) $\dagger$ & 0.233 & Normal $(0.233,0.0032)$ & 16 \\
\hline Stroke (temporary disutility) $\dagger$ & 0.1385 & Normal $(0.1385,0.01)$ & 15,17 \\
\hline Stroke (temporary duration, years) $\dagger$ & $1 / 12$ & Uniform $(0,0.183)$ & 17 \\
\hline Myocardial infarction (permanent disutility) & 0.0409 & Normal $(0.0409,0.002)$ & 15 \\
\hline Myocardial infarction (temporary disutility) & 0.1247 & Normal $(0.1247,0.01)$ & 15,17 \\
\hline Myocardial infarction (temporary duration, years) & $1 / 12$ & Uniform $(0,0.183)$ & 17 \\
\hline Intracranial haemorrhage (permanent disutility) & 0.0524 & Normal $(0.0524,0.001)$ & 15 \\
\hline Pulmonary embolism (temporary disutility) & 0.1385 & Normal $(0.1385,0.01)$ & 15,17 \\
\hline Pulmonary embolism (temporary duration, years) & $1 / 12$ & Uniform $(0,0.183)$ & 17 \\
\hline Transient ischaemic attack (temporary disutility) & 0.1032 & Normal $(0.1032,0.01)$ & 15,17 \\
\hline Transient ischaemic attack (temporary duration, years) & $5 / 365$ & Uniform $(0,0.027)$ & 17 \\
\hline Major bleed (temporary disutility) & 0.1385 & Normal $(0.1385,0.01)$ & 15,17 \\
\hline Major bleed (temporary duration, years) & $1 / 12$ & Uniform $(0,0.183)$ & 17 \\
\hline Minor bleed (temporary disutility) & 0.06 & Normal $(0.06,0.01)$ & 17 \\
\hline Minor bleed (temporary duration, years) & $5 / 365$ & Uniform $(0,0.027)$ & 17 \\
\hline Warfarin disutility & 0.013 & $\mathrm{Y}(1.3,0.01)$ & 16 \\
\hline Dabigatran disutility & 0.002 & $\mathrm{Y}(0.2,0.01)$ & Assumption \\
\hline Aspirin disutility & 0.002 & $\mathrm{Y}(0.2,0.01)$ & 16 \\
\hline \multicolumn{4}{|l|}{ Costs } \\
\hline Stroke-year $1 \dagger$ & $£ 10543.36$ & $Y(102.68,102.68)$ & 18 \\
\hline Stroke-subsequent years $\dagger$ & $£ 2781.22$ & Y $(52.74,52.74)$ & 18 \\
\hline Myocardial infarction-year 1 & $£ 2357.13$ & $Y(58.26,40.46)$ & 18 \\
\hline Myocardial infarction-subsequent years & $£ 828.90$ & $Y(34.55,23.99)$ & 18 \\
\hline Pulmonary embolism & $£ 1543.27$ & NA & 19 \\
\hline Transient ischaemic attack & $£ 839.62$ & NA & 19 \\
\hline Major bleed & $£ 1684.58$ & NA & 20 \\
\hline Minor bleed & $£ 93.17$ & NA & 20 \\
\hline Proton pump inhibitors ( 1 year) & $£ 185.20$ & NA & 21 \\
\hline Warfarin—drugs (1 year) & $£ 41.23$ & Uniform $(32.98,49.48)$ & 22,23 \\
\hline Warfarin-monitoring (1 year) & $£ 198.39$ & $\mathrm{Y}(202.59,0.979)$ & 22 \\
\hline Dabigatran-both doses (1 year) & $£ 919.80$ & NA & 24 \\
\hline Aspirin (1 year) & $£ 7.39$ & $\mathrm{Y}(73.9,0.1)$ & 17,23 \\
\hline \multicolumn{4}{|l|}{ Discount rate } \\
\hline Utilities & $3.5 \%$ & NA & 25 \\
\hline Costs & $3.5 \%$ & NA & 25 \\
\hline
\end{tabular}




\section{Table 1 (continued)}

Parameter

Value

Probabilistic sensitivity analysis distribution

References

$\mathrm{NA}=$ not applicable

*Proportion in initial population.

tIncludes both strokes and systemic emboli, excluding pulmonary emboli. 


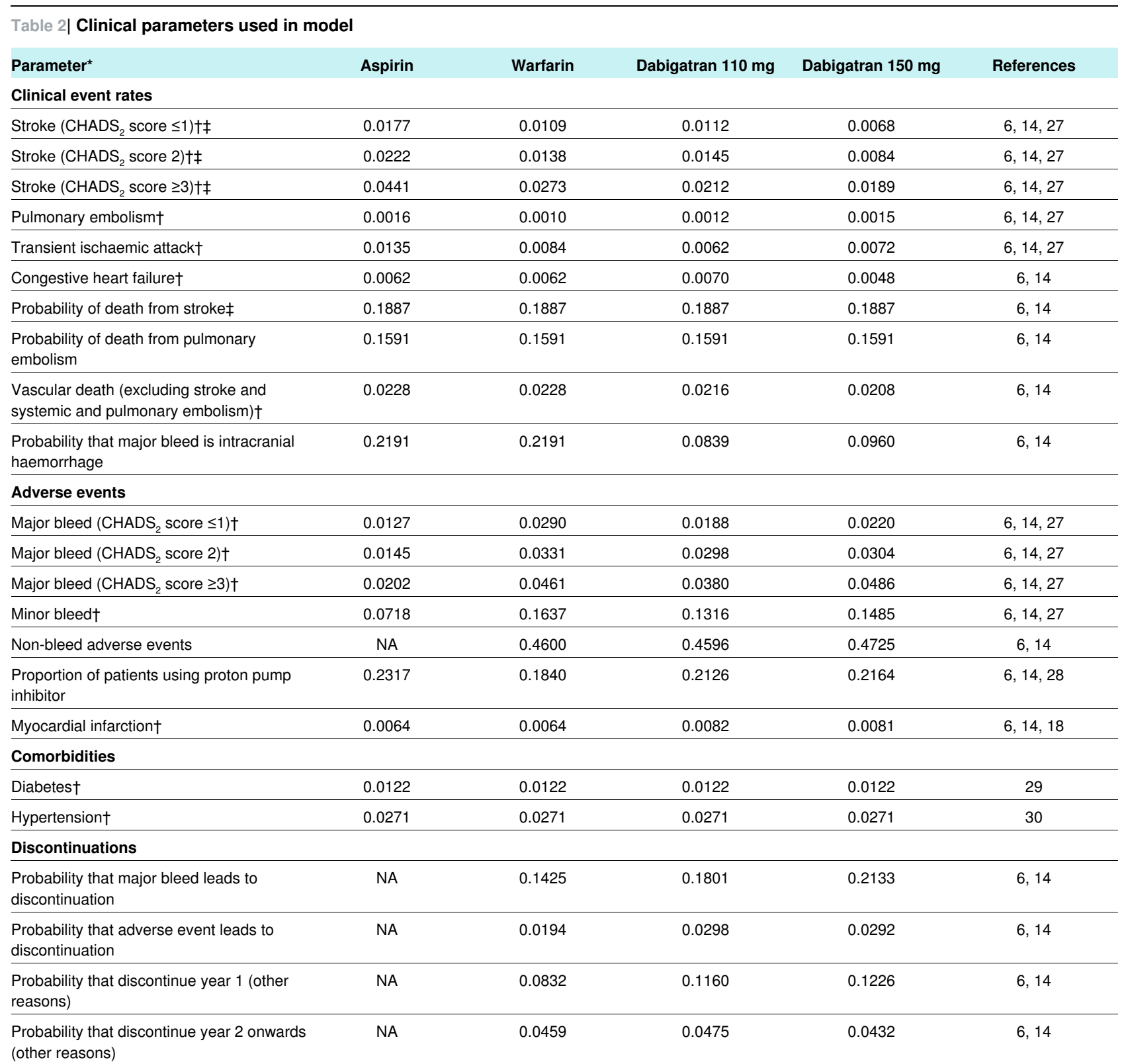

$\mathrm{CHADS}_{2}=$ Congestive heart failure, Hypertension, Age $\geq 75$ years, Diabetes mellitus, previous Stroke/transient ischaemic attack; NA=not applicable. ${ }^{*}$ See web extra table B for parameters specifying distributions for probabilistic sensitivity analysis.

†Presented as rates per 100 person years.

łIncludes both strokes and systemic emboli but not pulmonary emboli. 
Table 3/ Lifetime estimates of event rates, net benefits, and incremental differences versus comparator, derived from probabilistic sensitivity analysis

\begin{tabular}{|c|c|c|c|}
\hline Referent & Mean $(95 \%$ central range) estimate & Mean $\left(95 \%\right.$ central range) difference ${ }^{*}$ & Comparator \\
\hline \multicolumn{4}{|c|}{ Quality adjusted life years (QALYs) $†$} \\
\hline Warfarin & $6.390(6.265$ to 6.517$)$ & $-0.094(0.083$ to -0.267$)$ & Dabigatran $110 \mathrm{mg}$ bid \\
\hline Dabigatran $110 \mathrm{mg}$ bid & $6.484(6.360$ to 6.634$)$ & $-0.049(0.126$ to -0.221$)$ & Dabigatran age adjusted $\neq$ \\
\hline Dabigatran age adjusted $\ddagger$ & $6.531(6.401$ to 6.664$)$ & $-0.005(0.171$ to -0.180$)$ & Dabigatran $150 \mathrm{mg}$ bid \\
\hline Dabigatran $150 \mathrm{mg}$ bid & $6.536(6.413$ to 6.662$)$ & $0.146(-0.029$ to 0.322$)$ & Warfarin \\
\hline \multicolumn{4}{|l|}{ Life yearst } \\
\hline Warfarin & 10.851 (10.687 to 11.018$)$ & $-0.089(0.142$ to -0.323$)$ & Dabigatran $110 \mathrm{mg}$ bid \\
\hline Dabigatran $110 \mathrm{mg}$ bid & $10.940(10.776$ to 11.111$)$ & $-0.102(0.129$ to -0.338$)$ & Dabigatran age adjusted $\neq$ \\
\hline Dabigatran age adjusted $\neq$ & $11.042(10.873$ to 11.221$)$ & $-0.009(0.243$ to -0.232$)$ & Dabigatran $150 \mathrm{mg}$ bid \\
\hline Dabigatran $150 \mathrm{mg}$ bid & 11.051 (10.885 to 11.220$)$ & $0.200(-0.035$ to 0.429$)$ & Warfarin \\
\hline \multicolumn{4}{|c|}{ Stroke or systemic embolism (excluding pulmonary emboli) } \\
\hline Warfarin & 0.2408 (0.2010 to 0.2841$)$ & $0.0302(-0.0260$ to 0.0875$)$ & Dabigatran $110 \mathrm{mg}$ bid \\
\hline Dabigatran $110 \mathrm{mg}$ bid & $0.2107(0.1698$ to 0.2538$)$ & $0.0308(-0.0268$ to 0.0893$)$ & Dabigatran age adjusted $\neq$ \\
\hline Dabigatran age adjusted $\neq$ & $0.1799(0.1401$ to 0.2245$)$ & $0.0044(-0.0476$ to 0.0511$)$ & Dabigatran $150 \mathrm{mg}$ bid \\
\hline Dabigatran $150 \mathrm{mg}$ bid & $0.1755(0.1354$ to 0.2196$)$ & $-0.0654(-0.0092$ to -0.1226$) \S$ & Warfarin \\
\hline \multicolumn{4}{|l|}{ Ischaemic stroke } \\
\hline Warfarin & $0.1718(0.1484$ to 0.1982$)$ & $-0.0045(-0.0565$ to 0.0493$)$ & Dabigatran $110 \mathrm{mg}$ bid \\
\hline Dabigatran $110 \mathrm{mg}$ bid & 0.1763 (0.1507 to 0.2067$)$ & $0.0331(-0.0189$ to 0.0822$)$ & Dabigatran age adjusted $\neq$ \\
\hline Dabigatran age adjusted $\neq$ & $0.1432(0.1167$ to 0.1708$)$ & $0.0044(-0.0502$ to 0.0570$)$ & Dabigatran $150 \mathrm{mg}$ bid \\
\hline Dabigatran $150 \mathrm{mg}$ bid & 0.1388 (0.1121 to 0.1662$)$ & $-0.0330(0.0261$ to -0.0803$)$ & Warfarin \\
\hline \multicolumn{4}{|l|}{ Transient ischaemic attack } \\
\hline Warfarin & $0.1643(0.1281$ to 0.2074$)$ & $0.0218(-0.0280$ to 0.0712$)$ & Dabigatran $110 \mathrm{mg}$ bid \\
\hline Dabigatran $110 \mathrm{mg}$ bid & $0.1425(0.1057$ to 0.1791$)$ & $0.0273(-0.0237$ to 0.0762$)$ & Dabigatran age adjusted $\neq$ \\
\hline Dabigatran age adjusted $\neq$ & $0.1152(0.0791$ to 0.1509$)$ & $0.0042(-0.0449$ to 0.0580$)$ & Dabigatran $150 \mathrm{mg}$ bid \\
\hline Dabigatran $150 \mathrm{mg}$ bid & $0.1110(0.0744$ to 0.1476$)$ & $-0.0533(-0.0035$ to -0.1027$) \S$ & Warfarin \\
\hline \multicolumn{4}{|l|}{ Intracranial haemorrhage } \\
\hline Warfarin & $0.0756(0.0655$ to 0.0835$)$ & $0.0479(0.0347$ to 0.0614$) \S$ & Dabigatran $110 \mathrm{mg}$ bid \\
\hline Dabigatran $110 \mathrm{mg}$ bid & $0.0277(0.0240$ to 0.0308$)$ & $-0.0062(-0.0191$ to 0.0077$)$ & Dabigatran age adjusted $\ddagger$ \\
\hline Dabigatran age adjusted $\neq$ & $0.0339(0.0298$ to 0.0372$)$ & $-0.0017(-0.0133$ to 0.0116$)$ & Dabigatran $150 \mathrm{mg}$ bid \\
\hline Dabigatran $150 \mathrm{mg}$ bid & $0.0356(0.0322$ to 0.0391$)$ & $-0.0400(-0.0271$ to -0.0578$) \S$ & Warfarin \\
\hline \multicolumn{4}{|c|}{ Major bleed (including intracranial haemorrhage) } \\
\hline Warfarin & $0.3313(0.2942$ to 0.3766$)$ & $0.0133(-0.0409$ to 0.0673$)$ & Dabigatran $110 \mathrm{mg}$ bid \\
\hline Dabigatran $110 \mathrm{mg}$ bid & $0.3180(0.2811$ to 0.3623$)$ & $-0.0379(-0.0902$ to 0.0257$)$ & Dabigatran age adjusted $\neq$ \\
\hline Dabigatran age adjusted $\ddagger$ & 0.3559 (0.3180 to 0.3985$)$ & $-0.0048(-0.0561$ to 0.0512$)$ & Dabigatran $150 \mathrm{mg}$ bid \\
\hline Dabigatran $150 \mathrm{mg}$ bid & 0.3607 (0.3233 to 0.4017$)$ & $0.0294(0.0835$ to -0.0247$)$ & Warfarin \\
\hline \multicolumn{4}{|c|}{ Non-fatal myocardial infarction } \\
\hline Warfarin & $0.0612(0.0434$ to 0.0813$)$ & $-0.0109(-0.0346$ to 0.0126$)$ & Dabigatran $110 \mathrm{mg}$ bid \\
\hline Dabigatran $110 \mathrm{mg}$ bid & 0.0721 (0.0560 to 0.0895$)$ & $-0.0006(-0.0251$ to 0.0256$)$ & Dabigatran age adjusted $\neq$ \\
\hline Dabigatran age adjusted $\neq$ & $0.0727(0.0560$ to 0.0914$)$ & $-0.0003(-0.0250$ to 0.0255$)$ & Dabigatran $150 \mathrm{mg}$ bid \\
\hline Dabigatran $150 \mathrm{mg}$ bid & $0.0730(0.0561$ to 0.0934$)$ & $0.0119(0.0356$ to -0.0116$)$ & Warfarin \\
\hline
\end{tabular}

bid=twice daily.

${ }^{*}$ Difference from comparator group.

†Discounted at $3.5 \%$ per annum.

$\ddagger$ Age adjusted dabigatran dosing regimen ( $110 \mathrm{mg}$ bid for patients aged $\geq 80$ years) based on post hoc subgroup analysis.

$\S 95 \%$ central range for incremental difference does not cross zero. 


\begin{tabular}{|c|c|c|c|c|c|c|c|}
\hline \multirow[b]{2}{*}{ Subgroup } & \multirow[b]{2}{*}{$\begin{array}{l}\text { Warfarin cost } \\
(\mathfrak{(})\end{array}$} & \multirow[b]{2}{*}{$\begin{array}{l}\text { Warfarin } \\
\text { QALYs }\end{array}$} & \multirow[b]{2}{*}{$\begin{array}{l}\text { Dabigatran } 150 \\
\text { mg bid cost }(£)\end{array}$} & \multirow[b]{2}{*}{$\begin{array}{l}\text { Dabigatran } 150 \\
\text { mg bid QALYs }\end{array}$} & \multirow[b]{2}{*}{ ICER ( $($ /QALY) } & \multicolumn{2}{|c|}{ Probability of cost effectiveness } \\
\hline & & & & & & $\begin{array}{l}\text { At £20 } 000 \text { per } \\
\text { QALY }\end{array}$ & $\begin{array}{c}\text { At } £ 30000 \text { per } \\
\text { QALY }\end{array}$ \\
\hline RE-LY population & 6480 & 6.390 & 9850 & 6.536 & 23082 & 0.449 & 0.596 \\
\hline $\mathrm{CHADS}_{2}$ score 2 & 7412 & 6.283 & 10443 & 6.433 & 20207 & 0.475 & 0.615 \\
\hline $\mathrm{CHADS}_{2}$ score $\geq 3$ & 9912 & 6.224 & 12646 & 6.396 & 15895 & 0.565 & 0.683 \\
\hline $\begin{array}{l}\text { Centres' time in therapeutic } \\
\text { range } \geq 65.5 \%\end{array}$ & 6247 & 6.517 & 9977 & 6.605 & 42386 & 0.137 & 0.309 \\
\hline $\begin{array}{l}\text { Centres' time in therapeutic } \\
\text { range }<65.5 \%\end{array}$ & 6617 & 6.261 & 9656 & 6.410 & 20396 & 0.469 & 0.636 \\
\hline $\begin{array}{l}\text { Patients' time in therapeutic } \\
\text { range } \geq 66.8 \%\end{array}$ & 6302 & 6.401 & 9850 & 6.536 & 26281 & 0.393 & 0.511 \\
\hline $\begin{array}{l}\text { Patients' time in therapeutic } \\
\text { range }<66.8 \%\end{array}$ & 6694 & 6.360 & 9850 & 6.536 & 17932 & 0.519 & 0.643 \\
\hline $\begin{array}{l}\text { Creatinine clearance }<30-50 \\
\mathrm{~mL} / \mathrm{min}\end{array}$ & 7991 & 6.310 & 10788 & 6.460 & 18647 & 0.501 & 0.631 \\
\hline $\begin{array}{l}\text { Previous stroke or transient } \\
\text { ischaemic attack }\end{array}$ & 10004 & 6.217 & 12787 & 6.378 & 17286 & 0.525 & 0.649 \\
\hline Vitamin $\mathrm{K}$ antagonist naive & 6437 & 6.396 & 9792 & 6.545 & 22517 & 0.446 & 0.587 \\
\hline Age $\geq 75$ years & 4612 & 4.275 & 7362 & 4.429 & 17857 & 0.498 & 0.635 \\
\hline
\end{tabular}

bid=twice daily; $\mathrm{CHADS}_{2}=$ Congestive heart failure, Hypertension, Age $\geq 75$ years, Diabetes mellitus, previous Stroke/transient ischaemic attack; ICER=incremental cost effectiveness ratio; QALY=quality adjusted life year; RE-LY=Randomized Evaluation of Long-Term Anticoagulation Therapy.

*Proportion of simulations in which dabigatran $150 \mathrm{mg}$ twice daily is cost effective versus warfarin. 


\section{Figures}

\section{Warfarin $v$ dabigatran $110 \mathrm{mg}$ twice daily}

Stroke rates-warfarin $(\mathrm{L} / \mathrm{H})$ Stroke rates-dabigatran $(\mathrm{H} / \mathrm{L})$ Dabigatran benefit limited to 2 years Vascular death rates-warfarin $(\mathrm{L} / \mathrm{H})$ Vascular death rates-dabigatran $(\mathrm{H} / \mathrm{L})$ Drug utility losses (none) Event utility losses $(\mathrm{L} / \mathrm{H})$ Linear reduction in benefit (dabigatran) Bleed rates-warfarin $(\mathrm{L} / \mathrm{H})$ Bleed rates (unstratified by $\mathrm{CHADS}_{2}$ score) Bleed rates-dabigatran $(H / L)$ Correlated initial health states* Discontinuation rates $(\mathrm{H} / \mathrm{L})$ Discount rates $(\mathrm{H} / \mathrm{L})$

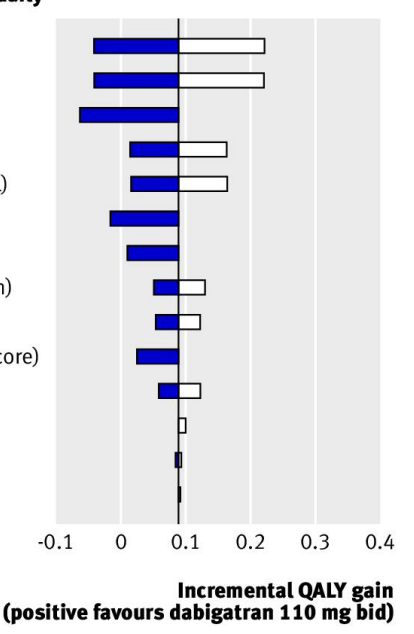

(positive favours dabigatran $110 \mathrm{mg}$ bid)
Warfarin $v$ dabigatran $150 \mathrm{mg}$ twice daily

Stroke rates-warfarin $(\mathrm{L} / \mathrm{H})$

Stroke rates-dabigatran $(\mathrm{H} / \mathrm{L})$

Dabigatran benefit limited to 2 years

Vascular death rates-warfarin $(\mathrm{L} / \mathrm{H})$

Vascular death rates-dabigatran $(H / L)$

Drug utility losses (none)

Event utility losses $(\mathrm{L} / \mathrm{H})$

Linear reduction in benefit (dabigatran)

Bleed rates-dabigatran $(\mathrm{H} / \mathrm{L})$

Bleed rates-warfarin $(\mathrm{L} / \mathrm{H})$

Bleed rates (unstratified by $\mathrm{CHADS}_{2}$ score)

Correlated initial health states*

Discontinuation rates $(\mathrm{H} / \mathrm{L})$

Discount rates $(\mathrm{H} / \mathrm{L})$

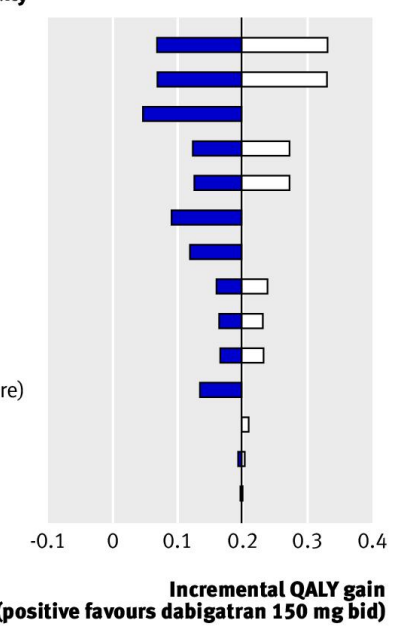

Dabigatran $150 \mathrm{mg}$ twice daily $\mathrm{v}$ warfarin

Stroke rates-warfarin $(\mathrm{H} / \mathrm{L})$

Stroke rates-dabigatran $(\mathrm{L} / \mathrm{H})$

Dabigatran benefit limited to 2 years

Vascular death rates-warfarin $(\mathrm{H} / \mathrm{L})$

Vascular death rates-dabigatran $(\mathrm{L} / \mathrm{H})$

Drug utility losses (none)

Event costs $(H / L)$

Event utility losses $(\mathrm{L} / \mathrm{H})$

Linear reduction in benefit (dabigatran)

Bleed rates-warfarin $(\mathrm{H} / \mathrm{L})$

Drug and monitoring costs-warfarin (H/L)

Bleed rates-dabigatran $(\mathrm{L} / \mathrm{H})$

Bleed rates (unstratified by $\mathrm{CHADS}_{2}$ score)

Dabigatran bleed cost (prothrombin complex concentrates)

Dabigatran discontinuers switched to aspirin (50\%)

Correlated initial health states*

Discontinuation rates $(\mathrm{L} / \mathrm{H})$

Discount rates $(\mathrm{L} / \mathrm{H})$

Fig 1 Tornado plot of univariate sensitivity analyses. First three panels relate to benefit-harm analyses; lower right panel relates to economic comparison of dabigatran $150 \mathrm{mg}$ twice daily and dose adjusted warfarin. $\mathrm{L}=$ lower end of $95 \% \mathrm{Cl}$ for parameter set; $\mathrm{H}=$ higher end of $95 \% \mathrm{Cl}$ for parameter set (see web extra table $\mathrm{A}$ ). bid=twice daily; $\mathrm{CHADS}_{2}=\mathrm{Con}$. heart failure, Hypertension, Age $\geq 75$ years, Diabetes mellitus, previous Stroke/transient ischaemic attack; ICER=incremental cost effectiveness ratio; QALY=quality adjusted life year. *Maximum deviation from all correlation structures tested, which occurred when all patients with hypertension were assumed to have diabetes and all patients with previous myocardial infarction were assumed to also have previous stroke

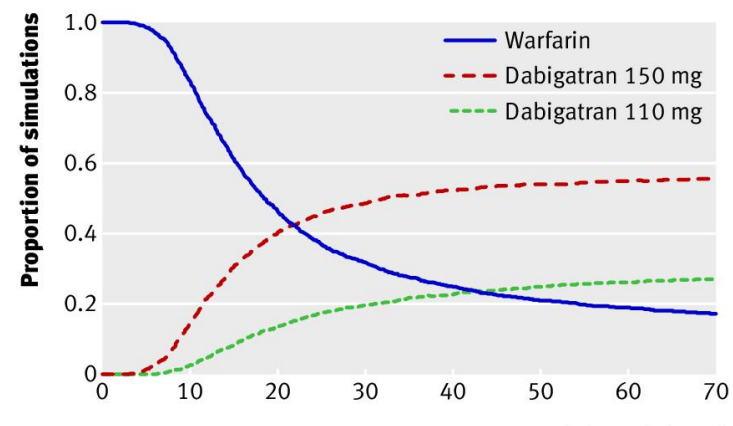

Cost effectiveness threshold (E/QALY) (000s)

Fig 2 Cost effectiveness acceptability curve for base case analysis. QALY=quality adjusted life year 
Incremental net health benefit (QALYs, 95\% CR)

RE-LY population $\mathrm{CHADS}_{2}$ score 2 CHADS $_{2}$ score $\geq 3$ Centre TTR $\geq 65.5 \%$ Centre TTR $<65.5 \%$ Patients $T R \geq 66.8 \%$ Patients TTR $<66.8 \%$ $\mathrm{CrCL} \ll 30-50 \mathrm{~mL} / \mathrm{min}$ Previous stroke or TIA Age $\geq 75$ years Vitamin $\mathrm{K}$ naive
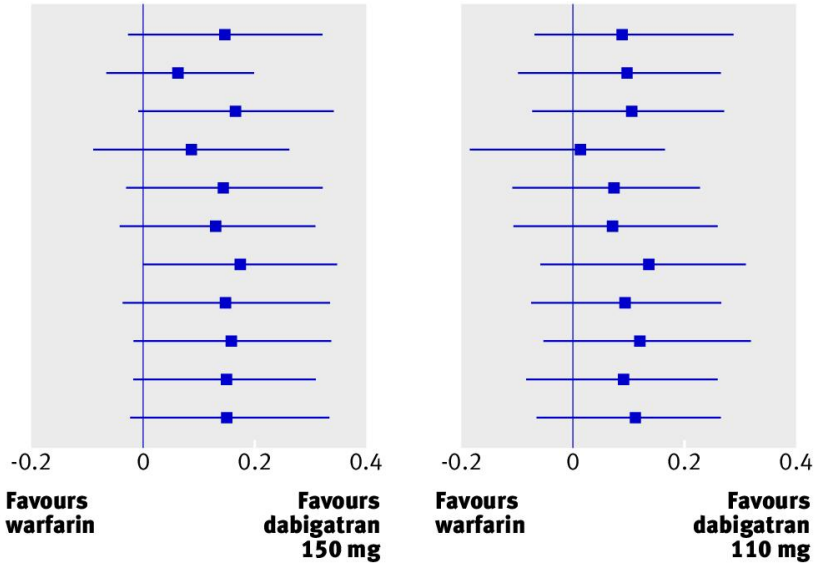

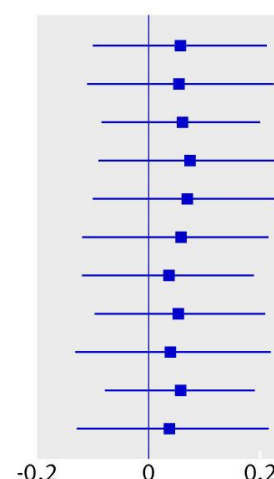

Favours dabigatran $110 \mathrm{mg}$

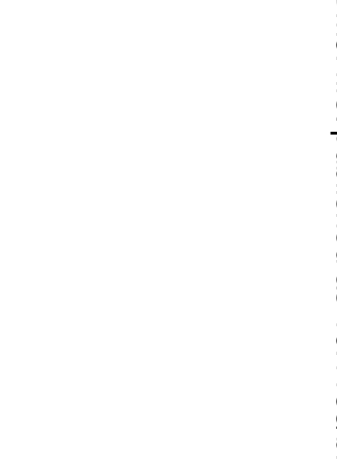

Fig 3 Results of probabilistic sensitivity analysis on efficacy and safety end points, expressed as incremental QALYs. Values are means and $95 \%$ central ranges from 2000 simulations. $\mathrm{CHADS}_{2}=$ Congestive heart failure, Hypertension, Age $\geq 75$ years, Diabetes mellitus, previous Stroke/transient ischaemic attack; $\mathrm{CrCl}=$ creatinine clearance; QALY=quality adjusted life year; RE-LY= Randomized Evaluation of Long-Term Anticoagulation Therapy; TIA=transient ischaemic attack; TTR=time within therapeutic range 